\title{
Rheological and Fluid Loss Properties of Water Based Drilling Mud Containing HCl-Modified Fufu as a Fluid Loss Control Agent
}

\author{
Samavati R., Abdullah N., Tahmasbi Nowtarki K., Hussain S. A., and Awang Biak D. R.
}

\begin{abstract}
Investigation on rheological and fluid loss properties of water based drilling mud containing acid modified fufu starch is presented. Hydrochloric acid at $8 \%$ and $16 \%$ was used, aiming at improving $f u f u$ performance as a fluid loss agent under extreme drilling temperature of $300 \mathrm{~F}$. Three formulations of mud weights of 75, 100 and 150 pcf were used, as proposed by the API and NISOC standards. Rheological properties, which are apparent viscosity, plastic viscosity, yield point and gel strength for the modified fufu showed significant improvement when $16 \%$ acid was employed. A significant amount of fluid loss reduction was obtained within light and average mud weights formulation (75pcf and 100pcf). Although none of the samples (modified and unmodified) meet the NISOC fluid loss standard requirement for the applied temperature, a great improvement was observed in ascending order of $16 \% \mathrm{HCl}>8 \% \mathrm{HCl}>$ unmodified $f u f u$ WBMs, accordingly.
\end{abstract}

Index Terms-Drilling mud, fluid loss, fufu, starch.

\section{INTRODUCTION}

In the petroleum industry starch is mostly applied in water based drilling muds (WBMs) as a fluid loss control additive. This is in favor of its low cost and easy accessibility. Conversely, starch application has been confronted by some restrictions, such as extreme brittleness, poor resistance in moisture, low processing capability (due to high viscosity) and irreconcilability with a number of hydrophobic polymers In view of that, to overcome these weakness numerous methods of modification have been proposed by different scientists thorough the years [1]-[5].

Modification of starch is defined as a procedure where starch configuration is changed by altering its hydrogen bond in a convenient manner. Typically, the degradation of starch may be made by numerous techniques like chemical modification, physical degradation, genetic alteration or enzymatic conversion. Chemical modification is by far the most

Starches which been chemically modified own major industrial importance, in their favor of glue manufacturing, chemical and industrial materials and also advancing practical properties of victuals and extra [6], [7]. There have been some studies based on physiochemical behaviors of numerous acid-alcohol modified starches such as potato, maize, wheat, sago and tapioca with some promising results.

Manuscript received January 20, 2014; revised March 6, 2014

Raheleh Samavati and Norhafizah Abdullah are with the Faculty of Chemical and Environmental Engineering, Universiti Putra Malaysia, 43400 UPM Serdang, Malaysia (e-mail: Samavati_Raheleh@yahoo.com, nhafizah@upm.edu.my).
[7]-[12]. Various chemical techniques such as hydrolysis, oxidation and cross linking were used to generate carbohydrates. Method of acid hydrolysis which goes back to more than 150 years involves starch suspension in an aqueous solution (sulfuric or hydrochloric acid) at definite temperatures. When a strong acid and heat come together, it will result in cleaving of the glycosidic bonds that link monosaccharides molecules together in the starch structure [7].

The chemical treatment of the starch is the most applied modification method for starches. In that category the acid-modified starches have some significant properties compared to unmodified starches such as: Subordinate molecular weight, extra linear molecules, Low viscosity (capable of be consumed at higher solids), superior gelling affinity, amplified paste clearness and advanced gelatinization temperature. Acid modification of starch suitable for industrial applications is usually prepared by Hydrochloric acid treatment [13], [14].

Fufu is made by steeping cassava roots in water for fermentation for period of 3 to 5 days depending on ambient temperature. After fermentation the products is well crushed and sieved to dry [15], [16]-[18].

The rheological and fluid loss evaluation of $f u f u$ as a fluid loss control agent in WBMs, based on American Petroleum Institute (API) and National Iranian South Oil Company (NISOC) standards for starch, have been previously studied in our group and revealed the potential of $f u f u$ as additive for fluid loss control functionality in water based drilling muds. An acceptable and compatible amount of fluid loss was reported in all the mud weights applied (75pcf, 100pcf and 150pcf) within the temperature of $250{ }^{\circ} \mathrm{F}$ [19]. When the drilling operation temperature is challenge to extreme condition of $300{ }^{\circ} \mathrm{F}$, all starches used in the WBM formulations (including potatoes, corn and cassava) were failed in their function as fluid loss agent [19].

With the visualization of improving the fluid loss control and thermal stability of cassava starch for WBMs formulation under extreme temperatures operation, we investigated the effect of acid modification on rheological and fluid loss properties of WBM samples containing treated $f u f u$ as a fluid loss agent.

\section{Methodology}

\section{A. Materials}

All the reagents applied in this research were analytical grade, purchased from Iran Kaolin and Barite Company (IKB Co.) in Tehran/Iran, whereas food grade $f u f u$ was precured 
from a local market Chow Kit in Kuala Lumpur, Malaysia. fufu starch was characterized using different techniques as presented in Table I below.

TABLE I: THE CHARACTERIZATION ANALYSIS OF FUFU

\begin{tabular}{|c|c|c|}
\hline Technique Applied & Samples Properties & Fufu \\
\hline Oven-Direct Heat & Humidity (\%) & 12.73 \\
\hline pH meter & $\mathrm{PH}$ & 5.43 \\
\hline $\begin{array}{c}\text { Digestion\& Distillation } \\
\text { System }\end{array}$ & Protein (\%) & 3.85 \\
\hline $\begin{array}{c}\text { Soxhlet Method } \\
\text { Muffle Furnace }\end{array}$ & Fat (\%) & 0.4 \\
\hline
\end{tabular}

\section{B. Preparation of Acid-Alcohol Treated Fufu}

Acid-alcohol treatment of fufu starch was conducted according to a method described by Robyt et al., 1996 [10], [20]. Briefly, a suspension from $2.5 \% \mathrm{w} / \mathrm{v}$ of cassava derivative fufu was prepared in anhydrous alcohol and treated with concentrated acid within $1-16 \% \mathrm{v} / \mathrm{v}$. The suspension was placed under isothermal condition in a water bath set at $68^{\circ} \mathrm{F}$ to $69.8^{\circ} \mathrm{F}$, for 2 hours. The acid modification was initiated adding appropriate volume of concentrated hydrochloric acid to the suspension under constant gentle mixing. In this study, we used two different volumes (8.0 and $16.0 \mathrm{~mL}$, which represent the medium and the maximum amount recommended by Robyt et al. 1996). Then, the starch suspension was left to dry for 7days at room temperature under gentle mixing. Then, the starch was filtered and washed with $70 \%$ ethanol for a couple of time until the $\mathrm{pH}$ drop to neutral. Then, the starch was air-dried prior ready to be used as mud additives.

\section{Preparation of Mud Samples}

Mud samples were prepared in 3 different mud weights (75, 100 and 150 pcf representing light, average and heavy weight, respectively) and their formulations were according to Table II. The rheological and fluid loss properties of mud samples containing the acid-modified $f u f u$ were investigated using the same method and environmental conditions as the unmodified fufu by Samavati et al. [19]. The mud was subjected to extreme drilling temperature via placing it a hot rolling oven at $300^{\circ} \mathrm{F}$ for $8 \mathrm{hr}$ under constant heating and circulation. Then, the mud samples were ejected and analyzed for their rheological and fluid loss properties.

TABLE II: THE COMPOSITION OF MUD SAMPLES

\begin{tabular}{|l|c|c|c|}
\hline \multicolumn{1}{|c|}{ Mud Composition } & $\begin{array}{c}\text { Light } \\
\text { Weight }\end{array}$ & $\begin{array}{c}\text { Average } \\
\text { Weight }\end{array}$ & $\begin{array}{c}\text { Heavy } \\
\text { Weight }\end{array}$ \\
\hline $\begin{array}{l}\text { Saturated Salt Water (Mud } \\
\text { base) }\end{array}$ & $350 \mathrm{cc}$ & $350 \mathrm{cc}$ & $350 \mathrm{cc}$ \\
\hline Fufu starch (Fluid loss agent) & $14 \mathrm{~g}$ & $14 \mathrm{~g}$ & $14 \mathrm{~g}$ \\
\hline Barite (Viscofier) & - & $226 \mathrm{~g}$ & $900 \mathrm{~g}$ \\
\hline Hematite (Viscofier) & - & - & $70 \mathrm{~g}$ \\
\hline Mud Weight & $75 \mathrm{pcf}$ & $100 \mathrm{pcf}$ & $150 \mathrm{pcf}$ \\
\hline
\end{tabular}

\section{Rheological and Fluid Loss Analysis of Drilling Mud}

The rheological characterization of the mud samples were carried out by measuring plastic viscosity (PV), yield point (YP), apparent viscosity (AV) and gel strength (GS) at 10sec and GS at 10min using OFITE viscometer (model 800, USA).
The volume of fluid loss was evaluated using a High Pressure-High Temperature filter press (HPHT) manufactured by Fann (model 3878, USA).

\section{RESUlTS AND DISCUSSION}

The influence of acid modification on fufu starch applied as a fluid loss control agent in WBMs towards rheological and fluid loss properties in different mud weights were investigated. The results on plastic viscosity (PV), yield point (YP), apparent viscosity (AV), Gel strength (Gs) and fluid loss were obtained for both the modified and unmodified fufu mud samples before and after being subjected to extreme temperature of $300 \mathrm{~F}$.

The experiments were carried out in 3 different mud weights $(75,100$ and $150 \mathrm{pcf})$, to represent NISOC standards applied for water based drilling muds in industrial formulations of exact on-shore drilling circumstances.

\section{A. The Effect of Acid Modification on Rheological Properties of WBM}

For better understanding on the influence of acid modification ( $\mathrm{HCl} 8 \%$ and $16 \%$ ) on drilling mud functional properties, the rheological evaluation of the modified samples was compared to the mud samples containing unmodified $f u f u$. The analyses were conducted in the same laboratory circumstances for both samples and shown in Table III and Table IV for mud with acid modified $(8 \% \mathrm{HCl}$ and $16 \% \mathrm{HCl})$, respectively. These are compared with the rheological properties of the unmodified $f u f u$ in different mud weights (Table V).

Table III showed rheological profile of $f u f u$ starch added to the 3 mud weight formulations (75,100 and 150pcf). The fufu was treated with $8 \% \mathrm{HCl}$ prior to the mud formulation. The $\mathrm{AV}$ and $\mathrm{PV}$ value in all mud samples was increased significantly after $8 \mathrm{hrs}$ hot rolls conditions at $300{ }^{\circ} \mathrm{F}$. The YP values in 75 and 150 pcf was dropped after the hot roll treatment, however, this was not observed in the 100pcf sample. For the GS at $1 \mathrm{~s}$ and $10 \mathrm{~min}$, the value remained unchanged after the $8 \mathrm{hrs}$ hot roll for the $75 \mathrm{pcf}$ sample. However, for the 100pcf and 150pcf samples, the GS values were found to increase and reduce, respectively. Meanwhile, the $\mathrm{pH}$ values in all the samples dropped to mild acidic after 8 hrs hot rolls treatment.

TABLE III: THE RHEOLOGICAL EVALUATION OF WBM CONTAINING MODIFIED FUFU ( $8 \%$-HCL) BEFORE HOT-ROLL (BHR) AND AFTER Hot-Roll (AHR) AT TEMPERATURE OF $300^{\circ}$ F IN DIFFERENT MUd

\begin{tabular}{|l|c|c|c|c|c|c|}
\cline { 2 - 7 } \multicolumn{1}{c|}{} & \multicolumn{2}{c}{$\mathbf{7 5}$ pcf } & \multicolumn{2}{c|}{ 100pcf } & \multicolumn{2}{c|}{ 150pcf } \\
\hline Rheology & BHR & AHR & BHR & AHR & BHR & AHR \\
\hline AV & 2 & $\mathbf{2 . 5}$ & 6 & $\mathbf{2 4}$ & 37 & $\mathbf{7 0 . 5}$ \\
\hline PV & 1 & $\mathbf{2}$ & 6 & $\mathbf{1 8}$ & 27 & $\mathbf{6 5}$ \\
\hline YP & 2 & $\mathbf{1}$ & 0 & $\mathbf{1 2}$ & 20 & $\mathbf{1 1}$ \\
\hline GS (10 s) & 1 & $\mathbf{1}$ & 1 & $\mathbf{3}$ & 18 & $\mathbf{1 1}$ \\
\hline $\begin{array}{l}\text { GS } \\
\text { (10min ) }\end{array}$ & 1 & $\mathbf{1}$ & 2 & $\mathbf{4}$ & 20 & $\mathbf{1 2}$ \\
\hline pH & 9.5 & $\mathbf{5}$ & 6.9 & $\mathbf{5 . 9}$ & 8.5 & $\mathbf{6}$ \\
\hline
\end{tabular}

When a higher strength of acid $(16 \% \mathrm{HCl})$ was used in the starch treatment, the rheological properties exhibited slight deviation in some of the mud formulations, than that observed in the $8 \% \mathrm{HCl}$. Table IV showed the overall rheological properties of three mud weight containing fufu 
that was pre-treated with $16 \% \mathrm{HCl}$. The AV value showed a significant increment after the hot roll. A linear trend in the $\mathrm{AV}$ property was observed as the mud weight composition is increased from 75 to 100 and 150 pcf. PV remained constant in $75 \mathrm{pcf}$, but significantly increased in the 100 and $150 \mathrm{pcf}$ samples, after the hot roll. YP for all the mud weight showed a consistent increment in its value while the GSs of 10s and 10 min remained constant after they are subjected to hot roll. Similar to the $8 \% \mathrm{HCL}$ formulation, the $\mathrm{pH}$ drop to mild acidic in all the formulations in the $16 \%$ HCL-treated sample

TABLE IV: THE RHEOLOGICAL EVALUATION OF WBM CONTAINING MODIFIED FUFU (16\%-HCL) BEFORE HOT-ROLL (BHR) AND AFTER Hot-Roll (AHR) AT TEMPERATURE OF $300^{\circ}$ F IN DiFFERENT MUD WEIGHTS

\begin{tabular}{|l|c|c|c|c|c|c|}
\cline { 2 - 7 } \multicolumn{1}{c|}{} & \multicolumn{2}{c|}{$\mathbf{7 5}$ pcf } & \multicolumn{2}{c|}{ 100pcf } & \multicolumn{2}{c|}{ 150pcf } \\
\hline Rheology & BHR & AHR & BHR & AHR & BHR & AHR \\
\hline AV & 1.5 & $\mathbf{2}$ & 5.5 & $\mathbf{8}$ & 21.5 & $\mathbf{2 5}$ \\
\hline PV & 1 & $\mathbf{1}$ & 5 & $\mathbf{7}$ & 18 & $\mathbf{2 3}$ \\
\hline YP & 1 & $\mathbf{2}$ & 1 & $\mathbf{2}$ & 7 & $\mathbf{4}$ \\
\hline GS (10 s) & 1 & $\mathbf{1}$ & 1 & $\mathbf{1}$ & 8 & $\mathbf{8}$ \\
\hline $\begin{array}{l}\text { GS } \\
\text { (10min ) }\end{array}$ & 1 & $\mathbf{1}$ & 1 & $\mathbf{1}$ & 9 & $\mathbf{9}$ \\
\hline pH & 8.9 & $\mathbf{5 . 5}$ & 8.1 & $\mathbf{6 . 4}$ & 9.1 & $\mathbf{7 . 1}$ \\
\hline
\end{tabular}

To make a fair comparison, a rheological performance of the untreated $f u f u$ starch was performed as well. This was presented in Table V. Here, it showed that a reduction in the $\mathrm{AV}$ value after the hot rolls for both 75 and 100 pcf samples. In contrast, the value was found to increase in the $150 \mathrm{pcf}$ sample. As for the PV, reduction in its values in $75 \mathrm{pcf}$ samples was observed, while increment in the 100 and 150 pcf sample, accordingly. The YP in 75pcf and 150pcf samples showed an increment, however not in the $100 \mathrm{pcf}$ sample (reduced it value). The GSs remained unchanged upon hot roll treatment for the 75pcf and 100pcf, but not in the 150pcf (showed a significant increment). Similar to all acid treated $f u f u$ formulations, the pHs of the untreated $f u f u$ formulations were dropped to mild acidic range.

TABLE V: THE RHEOLOGICAL EVALUATION OF WBM CONTAINING UNMODIFIED FuFU BEFORE HOT-ROLl (BHR) AND AFTER HOT-ROLl (AHR) AT TEMPERATURE OF $300^{\circ} \mathrm{F}$ IN DiFFERENT MUd WeIGHTS

\begin{tabular}{|l|c|c|c|c|c|c|}
\cline { 2 - 7 } \multicolumn{1}{c|}{} & \multicolumn{2}{c|}{75 pcf } & \multicolumn{2}{c|}{ 100pcf } & \multicolumn{2}{c|}{ 150pcf } \\
\hline Rheology & BHR & AHR & BHR & AHR & BHR & AHR \\
\hline AV & 2.5 & $\mathbf{2}$ & 11.5 & $\mathbf{7 . 5}$ & - & $\mathbf{4 0 . 5}$ \\
\hline PV & 2 & $\mathbf{1}$ & 7 & $\mathbf{8}$ & - & $\mathbf{3 6}$ \\
\hline YP & 1 & $\mathbf{2}$ & 7 & $\mathbf{1}$ & - & $\mathbf{9}$ \\
\hline GS (10 s) & 1 & $\mathbf{1}$ & 1 & $\mathbf{1}$ & - & $\mathbf{1 0}$ \\
\hline $\begin{array}{l}\text { GS } \\
\text { (10min ) }\end{array}$ & 1 & $\mathbf{1}$ & 1 & $\mathbf{1}$ & - & $\mathbf{1 1}$ \\
\hline pH & 7.6 & $\mathbf{6 . 5}$ & 7.6 & $\mathbf{6 . 4}$ & 7.4 & $\mathbf{6 . 3}$ \\
\hline
\end{tabular}

\section{B. Comparison of PV, AV, YP and GS Properties between Unmodified and Modified-Fufu Containing WBMs Formulation}

The four rheological properties evaluated for both treated and untreated fufu starch are PV, AV, YP and GS. These values were measured after $8 \mathrm{hrs}$ hot-rolling condition at 300 ${ }^{\circ} \mathrm{F}$, which simulate the extreme drilling operation condition. In other word, the following discussions are made based on AHR data from the Table III-Table V.

The AV value was set at $72 \pm 2 \mathrm{cp}$ for $150 \mathrm{pcf}$ mud weight by the NISOC standard. Note that, for the 75pcf and 100pcf mud weight, AV value is not available by this standard. The $\mathrm{AV}$ value increases as the mud weight increase (from 75 to
100 to $150 \mathrm{pcf}$ ) in all the samples (treated and untreated). None of the sample exhibited an acceptable AV values at the extreme $300{ }^{\circ} \mathrm{F}$ condition, set by the NISOC standard.

The PV value after hot-roll treatment for $8 \mathrm{hrs}$ under $300{ }^{\circ} \mathrm{F}$ for light mud weight formulations (75pcf) containing $8 \%$ HCL-treated, $16 \%$-HCL treat and untreated fufu starch showed very low value at 2,1 and $1 \mathrm{cp}$, respectively. With reference to the PV recommended under NISOC, value in the range of $15 \pm 2 \mathrm{cp}$ and $65 \pm 2 \mathrm{cp}$ for $100 \mathrm{pcf}$ and $150 \mathrm{pcf}$ mud weight must be met, respectively. However, no set value was made available for the $75 \mathrm{pcf}$ mud weight. The PV value increase as the mud weight increased. This is judged by the elevation of the PV from 2 to 18 to $65 \mathrm{cp}$ for $75 \mathrm{pcf}, 100 \mathrm{pcf}$ and $150 \mathrm{pcf}$ mud weight treated with the same strength of $8 \%$ $\mathrm{HCl}$ acid. Similar trend was also observed when dosage of acid used was doubled at $16 \%$, however the value was not as high as the $8 \%$ acid treated, which measured at 1 to 7 to 23 for $75 \mathrm{pcf}, 100 \mathrm{pcf}$ and 150pcf samples, respectively. The PV profile of $16 \%$ acid treated $f u f u$ was similar to the untreated fufu.

YP for $100 \mathrm{pcf}$ and $150 \mathrm{pcf}$ was set at $12 \pm 2 \mathrm{cp}$ and $18 \pm 2 \mathrm{cp}$, respectively. While, no YP value was available for the $75 \mathrm{pcf}$ mud weight. Unlike AV and PV, no increment trend was observed between YP and mud weight employed. The YP value was also outside acceptable range set by NISOC. However, some of them are acceptable under API standard (set value at $2 \mathrm{cp}$ ), such as the mud weight of 75 and 100pcf that were acid-treated (16\%) and in the unmodified fufu (at 75 pcf mud weight).

Under NISOC standard, acceptable value for GS (10s and $10 \mathrm{~min}$ ) is set at $3 \mathrm{lb} / 100 \mathrm{ft}^{2}$ and $4 \mathrm{lb} / 100 \mathrm{ft}^{2}$ for $100 \mathrm{pcf}$ and $150 \mathrm{pcf}$ mud weight formulation, respectively. Whereas there was no set value for GS of 75 pcf mud weight in the NISOC standard. In this study, only one formulation is acceptable under NISOC regulation, which is the $8 \%$ acid modified $f u f u$ in 100 pcf mud weight. The GS 10 s and $10 \mathrm{~min}$ in all treated and untreated $f u f u$ with light $(75 \mathrm{pcf})$ mud weight remained constant at $1 \mathrm{lb} / 100 \mathrm{ft}^{2}$. In the heavy (150pcf) mud formulation, all the sample was rejected since the GS values are higher than $4 \mathrm{lb} / 100 \mathrm{ft}^{2}$ (set by NISOC).

$\mathrm{pH}$ is another important criteria in the drilling operation. It is desirable to have mild-alkaline $\mathrm{pH}$ value (8.0 -9.5). Usually, this is achieved by adding limestone (if needed) to the mud formulation. The initial $\mathrm{pH}$ in the unmodified fufu in all the mud weight was around neutral $\mathrm{pH}$. This was observed consistently with other type of starch used in our laboratory (results unpublished). When the starch was treated with acid, the $\mathrm{pH}$ of the formulations increase to mild alkaline range, which was desirable by drilling practice. After 8 hrs hot roll operation at $300{ }^{\circ} \mathrm{F}$, the $\mathrm{pHs}$ in all the samples dropped to mild acidic-neutral value ( $\mathrm{pH} 5-7)$. Thus, requiring $\mathrm{pH}$ adjustment (preferably via lime addition), if further use of the mud is required.

\section{The Effect Acid Modification of Fufu on Fluid Loss}

Investigation on the fluid loss properties were carried out using an API proved High Pressure-High Temperature Filter Press (HPHT) manufactured by Fann (model 3878, USA). The NISOC standard requires acceptable amount of fluid loss for WBMs to not exceed 2mL. Fig. 1- Fig. 3 present the fluid loss evaluation of modified and unmodified $f u f u$ in different 
mud weights at the temperature of $300{ }^{\circ} \mathrm{F}$. All the mud samples containing modified and unmodified $f u f u$ failed to function as a fluid loss control additive, because their values exceeded the acceptable fluid loss limit (more than $2 \mathrm{~mL}$ ).

Even so, within the light WBM formulation (Fig. 1), a significant drop in fluid loss value was observed in modified fufu sample as compared to the unmodified, from $250 \mathrm{ml}$ (unmodified) to $130 \mathrm{ml}(8 \% \mathrm{HCl})$ and $100 \mathrm{ml}$ (in $16 \% \mathrm{HCl}$ ).

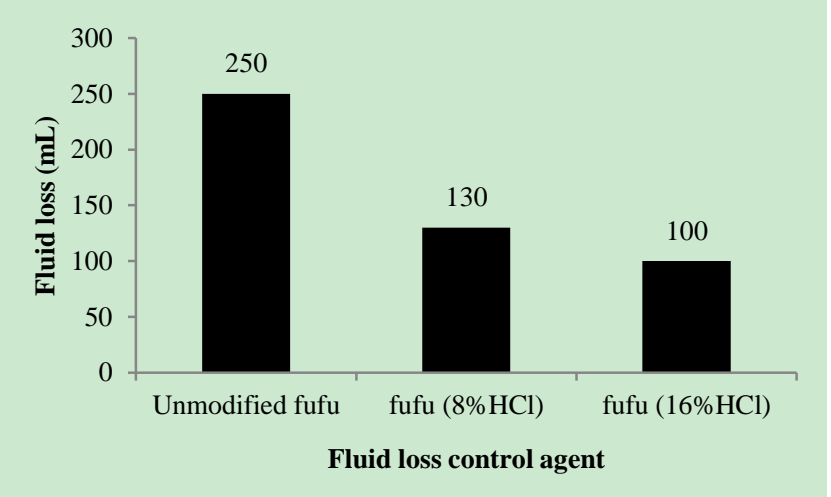

Fig. 1. The fluid loss evaluation of unmodified and acid modified fufu $(8 \% \mathrm{HCl}$ and $16 \% \mathrm{HCl})$ after hot-roll at $300 \mathrm{~F}$ in mud weight of $75 \mathrm{pcf}$.

In the average weight mud (Fig. 2), there was no improvement observed in a fluid loss value between untreated and $8 \%$ acid treated fufu. Doubling the acid strength $(16 \% \mathrm{HCl})$ resulted in a notable reduction in fluid loss by $\sim 66 \%$, however the value is still rejected by the NISOC standard.

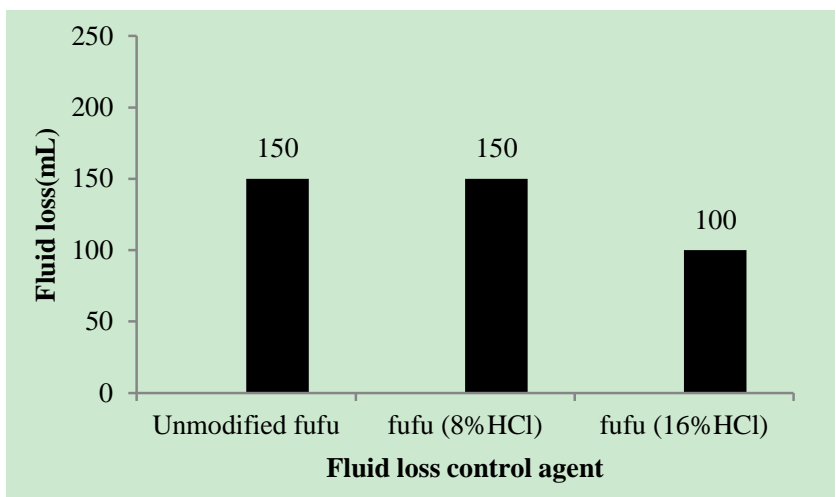

Fig. 2. The fluid loss evaluation of unmodified and acid modified fufu $(8 \% \mathrm{HCl}$ and $16 \% \mathrm{HCl})$ after hot-roll at $300^{\circ} \mathrm{F}$ in mud weight of $100 \mathrm{pcf}$.

Contradict to the fluid loss profile observed in light and average mud, the heavy mud formulation (Fig. 3) showed augmentation in the fluid loss when subjected to HCLmodification. This probably due to the increment in the mud composition in the formulation.

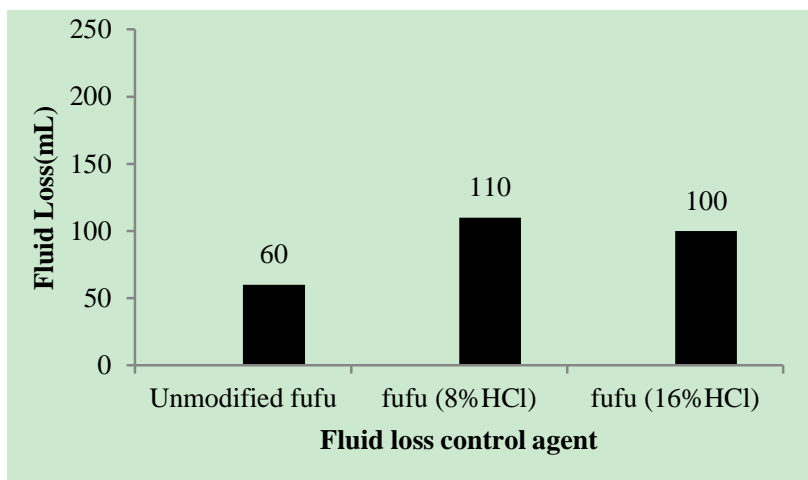

Fig. 3. The fluid loss evaluation of unmodified and acid modified fufu $(8 \% \mathrm{HCl}$ and $16 \% \mathrm{HCl})$ after hot-roll at $300^{\circ} \mathrm{F}$ in mud weight of $150 \mathrm{pcf}$.

\section{CONCLUSION}

HCl-modified $f u f u$ (cassava derivative) applied as an additive in WBMs formulation for use under the temperature of $300^{\circ} \mathrm{F}$ has shown a significant improvement as compared to that without acid-modification. A significant amount of fluid loss reduction was obtained within light and average mud weights formulation (75pcf and 100pcf). Although none of the samples (modified and unmodified) meet the NISOC fluid loss standard requirement (up to $2 \mathrm{~mL}$ of fluid loss) for the applied temperature, a great improvement was observed in ascending order of $16 \% \mathrm{HCl}>8 \% \mathrm{HCl}>$ unmodified $f u f u$ WBMs, accordingly.

\section{ACKNOWLEDGMENT}

The authors expressing their gratitude to PARS Drilling Fluid Company (Tehran/Iran), for provision of drilling mud laboratory and facilities in this investigation, and also to $\mathrm{Mr}$. Mojtaba Kalhor for his technical supervision and advisory for Ms. Raheleh Samavati.

\section{REFERENCES}

[1] R. Santayanon and J. Wootthikanokkhan, "Modification of Cassava Starch by Using Propionic Anhdride and Properties of Starch-blended Polyester Polyurethane," Carbohydrate Polymers, vol. 51, pp. 17-24, 2003.

[2] G. Oertel, Polyurethane Handbook: Chemistry-raw Materials-proccesing-Application-Properties, Polyurethane Handbook, Munich, Hanser, 1985.

[3] M. F. Koenig and S. J. Huang, "Evaluation of crosslinked poly(caprolactone) as a biodegradable, hydrophobic coating. polymer degradation and stability," vol. 45, issue 1, pp. 139-144, 1994.

[4] S. M. Goheen and R. P. Wool, "Degradation of Polyethylene- Starch Blends in Soil," Applied Polymer Science, vol. 42. pp. 2691-2701, 1991.

[5] J. M. Mayer and D. L. Kaplan, "Biodegradable Materials: Balancing Degradability and Performance," Trends in Polymer Science, vol. 2, no. 7, pp. 227, 1994.

[6] A. Guilbot and C. Mercier, The Polysaccharides, London: Academic Press, 1985.

[7] P. H. Yiu, S. L. Loh, A. Rajan, S. C. Wong, and C. F. G. Bong, "Physiochemical propertires of sago starch modified by acid treatment in alchohol," Applied Sciences, vol. 5. pp. 307-311, 2008.

[8] W. P. Ma and J. F. Robyt, "Preparation and characterization of soluble starches having different molecular sizes and composition, by acid hydrolysis in different alcohols," Carbohydrate Research, vol. 166. pp. 283-297, 1987,

[9] J. D. Fox and J. F. Robyt, "Modification of starch granules by hydrolysis with hydrochloric acid in various alcohols, and the formation of new kinds of limit dextrins," Carbohydrate Research, vol. 227. pp. 163-170, 1992.

[10] J. F. Robyt, J. Y. Choe, R. S. Hann, and E. B. Fuchs, "Acid modification of starch granules in alcohols: effects of temperature, acid concentration, and starch concentration," Carbohydrate Research, vol. 28. pp. 201-218, 1996.

[11] Y. L. Chung and H. M. Lai, "Molecular and granular characteristics of corn starch modified by hcl-methanol at different temperatures," Carbohydrate Polymers, vol. 63, pp. 527-534, 2006.

[12] J. H. Lin, S. Y. Lee, and Y. H. Chang, "Effect of acid-alcohol treatment on the molecular structure and physicochemical properties of maize and potato starches," Carbohydrate Polymers, vol. 53, pp. 475-482, 2003.

[13] O. B. Wurzburg, "Converted starches," in Modified Starches: Properties and Uses, O. B. Wurzburg, Ed., Boca Raton, Florida: CRC Press, 1986.

[14] V. Singh, and S. Z. Ali, "Acid degradation of starch. The effect of acid and starch type," Carbohydrate Polymers, vol. 41. pp. 191-195, 2000.

[15] A. O. Ogunsua, "Changes in some chemical constituents during the fermentation of cassava tubers (Manihot esculenta, Crantz)," Food Chemistry, vol. 5, no. 3, pp. 249-255, 1980.

[16] V. A. Oyenuga, Nigeria's Foods and Feeding-stuffs, 3rd Ed. Nigiria: Ibadan University Press, 1986. 
[17] O. B. Oyewole and S. Ayo Odunfa, "Effects of fermentation on the carbohydrate, mineral, and protein contents of cassava during "fufu" production," Food Composition and Analysis, vol. 2, no. 2, pp. 170-176, 1989.

[18] M. A. Ayankunbi, O. O. Keshinro, and P. Egele, "Effect of methods of preparation on the nutrient composition of some cassava products - Garri (eba), 'Lafun' and 'Fufu',' Food Chemistry, vol. 41, no. 3. pp. 349-354, 1991.

[19] R. Samavati, N. Abdullah, K. T. Nowtarki, S. A. Hussain, and D. R. Awang Biak, "The prospect of utilizing a cassava derivative (fufu) as a fluid loss agent in water based drilling muds," Chemical Engineering and Applications, vol. 5, no. 2. pp. 161-169, 2014.

[20] J. F. Robyt, J. Y. Choe, R. S. Hann, and E. B. Fuchs, "Acid modification of starch granules reactions in mixtures of two alcohols different ratios," Carbohydrate Research, vol. 283. pp. 141-150, 1996.

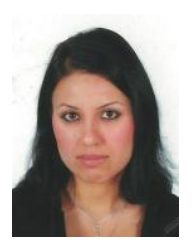

Raheleh Samavati is a $\mathrm{PhD}$ student at the Department of Chemical and Environmental Engineering (Material and Science Engineering), Universiti Putra Malaysia. Her research activities are in the area of starch based drilling fluids.

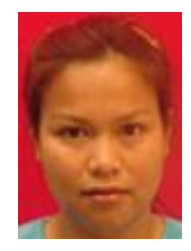

Norhafizah Abdullah is a lecturer at the Department of Chemical and Environmental Engineering, Universiti Putra Malaysia and the head of Material Characterization Laboratory at Faculty of Engineering, Universiti Putra Malaysia. Her research activities are in the area of purification engineering and macromolecules design for drug delivery and formulation. 